\title{
Report Version Document
}

National Cancer Institute

\section{Source}

National Cancer Institute. Report Version Document. NCI Thesaurus. Code C93380.

A document characterized by information or other content which is tailored to the context of a given situation and audience. 